\title{
Toxic Effects of Bis (Tributyltin) Oxide on the Synthesis and Secretion of Zymogen Granules in the Rat Exocrine Pancreas
}

\author{
Kazuo HARA ${ }^{1}$, Mitsuaki YoshizuKa ${ }^{2}$ and Sunao FuJIMoto ${ }^{1}$ \\ Department of Anatomy ${ }^{1}$, University of Occupational and Environmental Health School of Medicine, Kitakyushu; and \\ Department of Anatomy ${ }^{2}$, Kurume University School of Medicine, Kurume, Japan
}

Received January 14, 1994

\begin{abstract}
Summary. Toxic effects of bis (tributyltin) oxide (TBTO) on the rat exocrine pancreas were studied with an electron microscope and X-ray microanalyzer. To measure tin concentrations in the blood, atomic absorption spectrophotometry was carried out.

Adult male Wistar rats received an intramuscular injection of TBTO $(0.5 \mathrm{ml} / \mathrm{kg})$. At $2 \mathrm{~h}$ after injection, a marked swelling of mitochondria and an enlargement of the cisterns of the rough endoplasmic reticulum appeared in the pancreatic acinar cells. Using X-ray microanalysis, tin peaks were preferentially obtained from the swollen mitochondria. Heterogeneous zymogen granules with an electron dense core and a pale central zone increased in number in the acinar cells between 4 and $8 \mathrm{~h}$ after TBTO treatment. By $24 \mathrm{~h}$ after TBTO injection, the acinar cells had been ultrastructurally restored. Atomic absorption analyses showed that blood tin concentrations peaked at approximately $1 \mathrm{~h}$ after TBTO injection and then progressively declined, reaching the zero level at $12 \mathrm{~h}$ after injection.

The effects of TBTO on the synthesis and secretion of zymogen granules were investigated with and without caerulein as a stimulant of secretion. Data obtained from these experiments indicated that TBTO inhibited both the synthesis and secretion of zymogen granules. The inhibition of the protein synthesis and secretion might be caused partly by mitochondrial dysfunctions due to the toxic effects of TBTO.
\end{abstract}

Tributyltin compounds have been widely used in the fishing industry as antifouling paints for the bottoms of ships, and for fishing nets and cages. However, the toxic effects of these compounds on mammals have received much attention, since the accumulation of tributyltin compounds in cultured fishes was reported (WADA and MANABE, 1987), The biological effects of tributyltin compounds have recently been summar- ized (BOYER, 1989; WHO, 1990; HENSCHLER, 1991). Although there are a few reports on the toxic effects of some organo-tin compounds on the pancreas such as pancreatitis induced by dibutyltin salts in rats (BARNES and MAGEE, 1958; MERKORD et al., 1991), and diabetic lipemia induced by triphenyltin fluoride in rabbits (MANABE and WADA, 1981), ultrastructural studies of toxic effects of tributyltin compounds on the exocrine pancreas have not been available.

The present study was undertaken to elucidate the effects of bis (tributyltin) oxide (TBTO) on the synthesis and secretion process of zymogen granules in the rat exocrine pancreas.

\section{MATERIALS AND METHODS}

Animals

Adult male Wistar UOEH rats (weighing 250-300 g) were housed in individual stainless steel cages and maintained in a $12 \mathrm{~h}$ light-dark cycle. Exposure to light was from 6 to $18 \mathrm{~h}$. The animals completed a 18 $\mathrm{h}$ fast prior to dosing. All animals were fasted until sacrifice, but were permitted water ad libitum.

\section{Electron microscopy}

In our preliminary study, we found that a single intramuscular injection of $2 \mathrm{ml} / \mathrm{kg} \quad(2,340 \mathrm{mg} / \mathrm{kg})$ body weight of undiluted TBTO was the $\mathrm{LD}_{50}$ (lethal dose for the $50 \%$ survival group) in male Wistar rats. A quarter of the $\mathrm{LD}_{50}$ was chosen for the present study.

Twenty-seven adult male Wistar rats received an intramuscular injection of $0.5 \mathrm{ml} / \mathrm{kg}$ body weight of TBTO (Aldrich Chemical Co. Inc. WI, USA, purity: 
$96 \%$ ), and after time intervals of $0.5,1,2,4,6,8,12$, 18 , and $24 \mathrm{~h}$ from injection, the animals were deeply anesthetized with an injection of pentobarbital and each pancreas was isolated. Another nine male rats received an intramuscular injection of $0.5 \mathrm{ml} / \mathrm{kg}$ body weight of distilled water and served as controls. Specimens from all experiments were fixed in 3.5\% glutaraldehyde in $0.1 \mathrm{M}$ cacodylate buffer $(\mathrm{pH} 7.4)$ at $4^{\circ} \mathrm{C}$ for $2 \mathrm{~h}$, postfixed in $1 \%$ osmium tetroxide in the same buffer at $4^{\circ} \mathrm{C}$ for $2 \mathrm{~h}$, dehydrated in a graded series of acetone and embedded in epoxy resin. Ultrathin sections were stained by uranyl acetate and lead citrate and observed with a JEM 1200EX electron microscope.

\section{X-ray microanalysis}

In energy dispersive $\mathrm{X}$-ray microanalysis, frozen sections of tissues are usually utilized for the detection of cytoplasmic elements. However, in our preliminary experiment, tin L-alpha peaks $(3.44 \mathrm{keV})$ were completely covered by high potassium $\mathrm{K}$-alpha peaks $(3.31 \mathrm{keV})$ due to the persistance of the intracytoplasmic potassium ion in the frozen sections. Therefore, fixed and resin-embedded sections were utilized for the present study.

Nonstained ultrathin sections were analyzed for detection of the accumulation sites of TBTO in the pancreas tissue, using a JEM $2000 \mathrm{EX}$ electron microscope equipped with a LINK QX 200J energy dispersive X-ray microanalyzer.

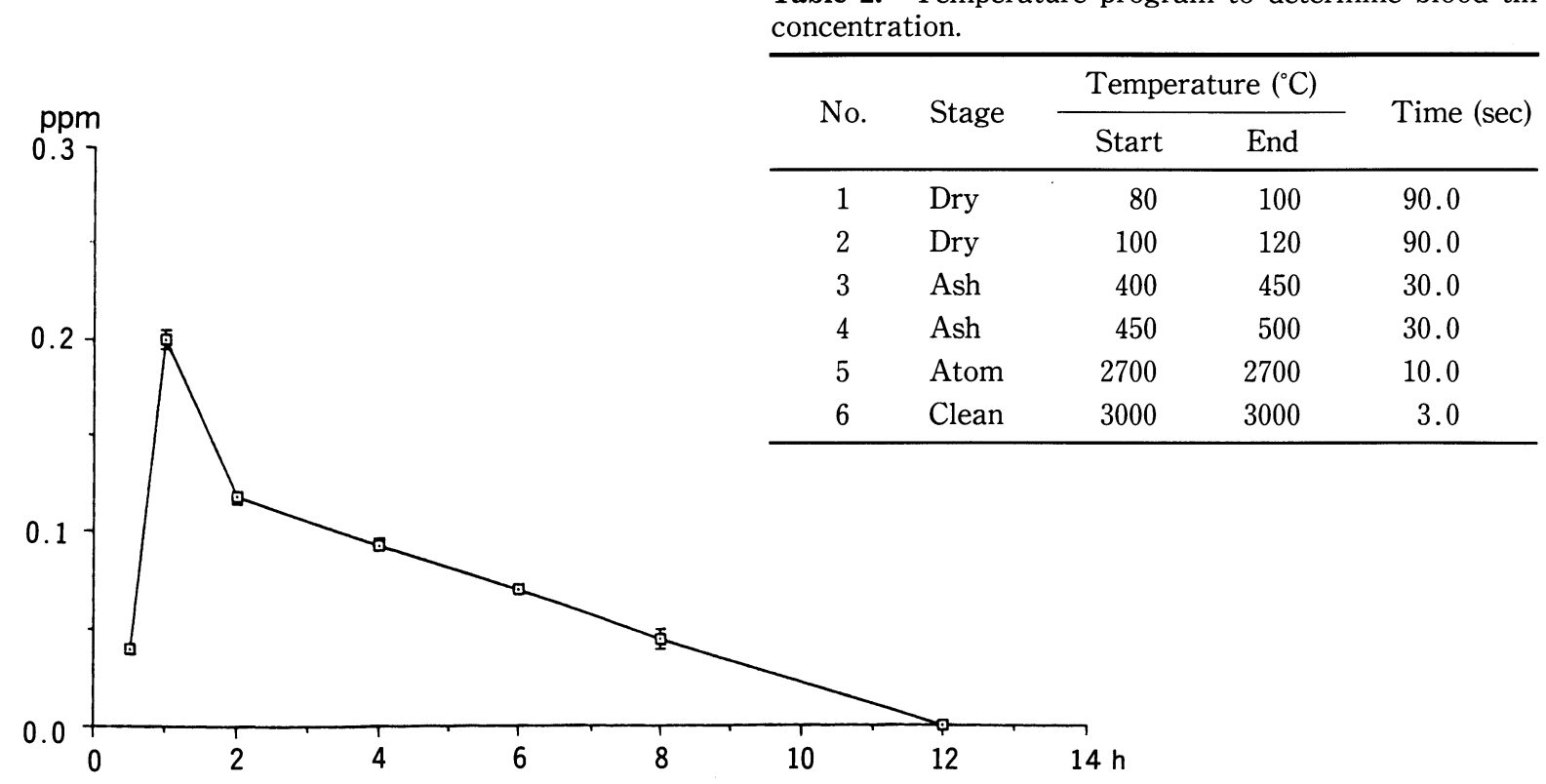

Fig. 1. Data from atomic absorption analyses of tin concentrations in the blood. All values are expressed as mean $\pm \mathrm{SD}$.

\section{Determination of tin concentration in the blood}

Twenty-seven male Wistar rats received an intramuscular injection of the same dose of TBTO as described above. At time intervals of $0.5,1,2,4,6,8$, 12,18 and $24 \mathrm{~h}$ after injection, the animals (three in each group) were deeply anesthetized with injection of pentobarbital, and blood samples were collected from the left ventricle. Whole blood was diluted fourfold with $3 \mathrm{~N} \mathrm{HCl}$ containing $10 \%$ ascorbic acid to prevent adverse effects of iron in determining the concentrations of tin.

The tin concentrations in the blood samples were then determined with a Hitachi Z-8000 Zeeman atomic absorption spectrophotometer. Instrumental operating conditions and temperature programs to determine tin concentrations in the blood are shown in Tables 1 and 2, respectively.

Table 1. Instrumental conditions to determine blood tin concentration.

$\begin{array}{lc}\text { Lamp current } & 10.0 \mathrm{~mA} \\ \text { Wave length } & 286.3 \mathrm{~nm} \\ \text { Slit } & 1.3 \mathrm{~nm} \\ \text { Cuvette } & \text { Tube } \\ \text { Carrier gas } & 200 \mathrm{ml} / \mathrm{min} \\ \text { Interrupted gas } & 30 \mathrm{ml} / \mathrm{min} \\ \text { Sample volume } & 10 \mu 1\end{array}$

Table 2. Temperature program to determine blood tin concentration.

\begin{tabular}{llrrr}
\hline \multirow{2}{*}{ No. } & Stage & \multicolumn{2}{c}{ Temperature $\left({ }^{\circ} \mathrm{C}\right)$} & \\
\cline { 3 - 4 } & & Start & End & \\
\hline 1 & Dry & 80 & 100 & 90.0 \\
2 & Dry & 100 & 120 & 90.0 \\
3 & Ash & 400 & 450 & 30.0 \\
4 & Ash & 450 & 500 & 30.0 \\
5 & Atom & 2700 & 2700 & 10.0 \\
6 & Clean & 3000 & 3000 & 3.0 \\
\hline
\end{tabular}



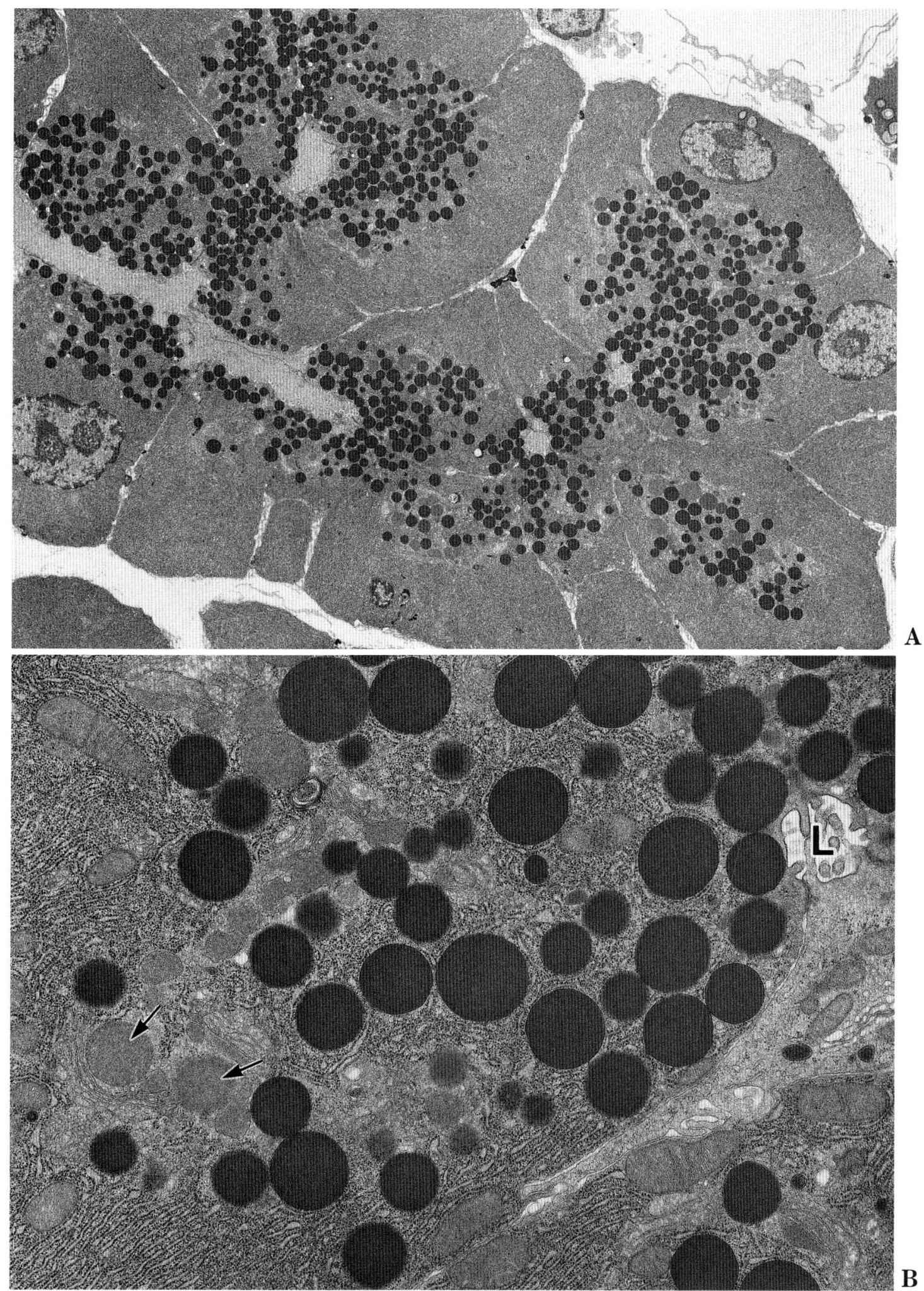

A

Fig. 2 A. An electron micrograph showing pancreatic acinar cells of control rat. Numerous electron dense zymogen granules exist in the apical cytoplasm and considerable numbers of rough surfaced endoplasmic reticulum occupy the basal cytoplasm. $\times 2,600$. B. Condensing vacuoles (arrows) in the region of the Golgi complexes show relatively low electron density. $L$ acinar lumen. $\times 12,000$ 


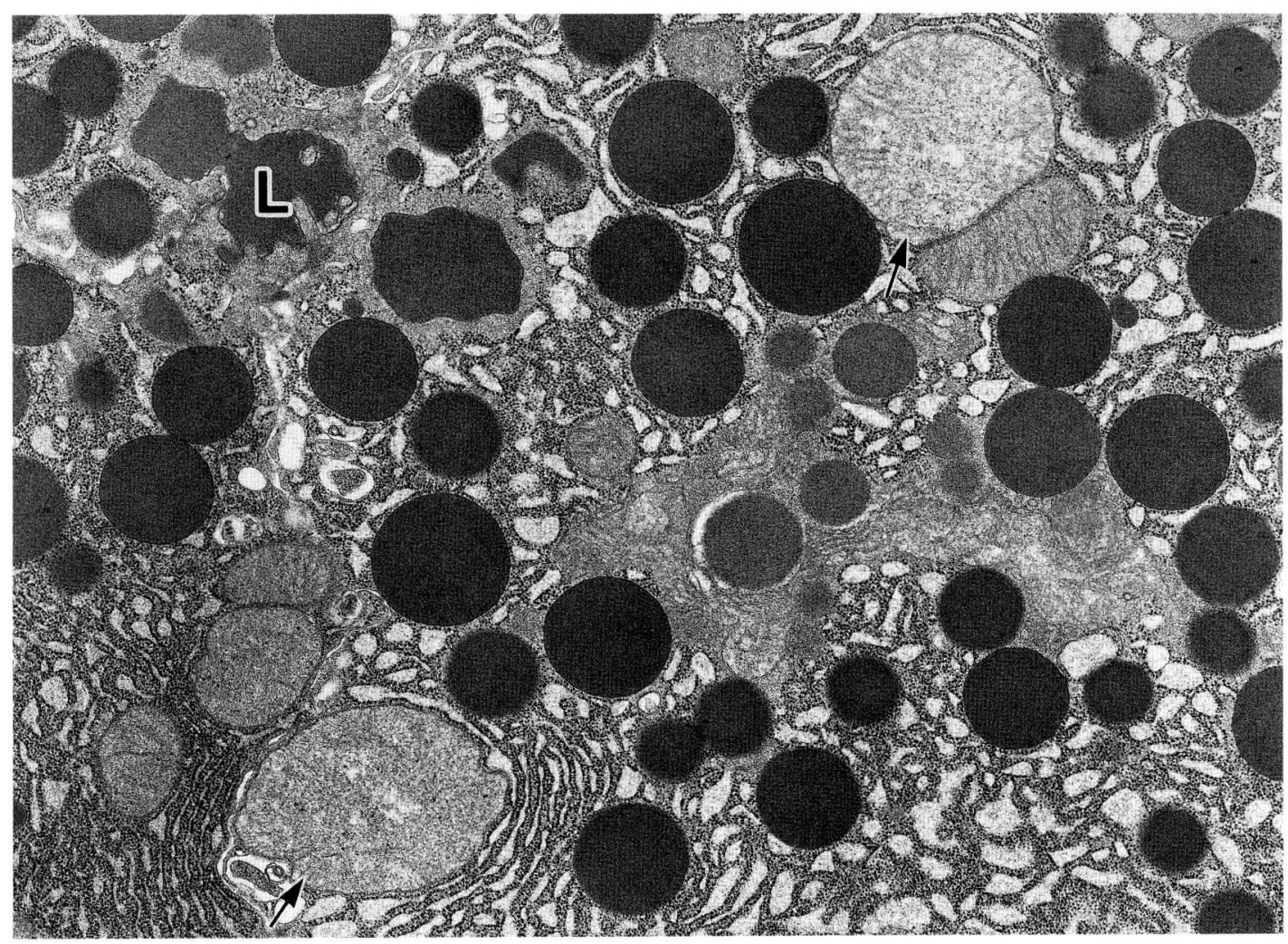

Fig. 3. Marked swelling of mitochondria (arrows) and enlargement of cisterns of rough surfaced endoplasmic reticulum appear in the acinar cell at $2 \mathrm{~h}$ after TBTO treatment. $L$ aciner lumen. $\times 10,000$

\section{Effects of TBTO on zymogen granule secretion and synthesis}

To clarify the effects of TBTO on the secretion and synthesis of zymogen granules of exocrine pancreatic acinar cells, caerulein (Cn), a cholecystokinin (CCK) analogue, was administered before or after TBTO treatment. In our preliminary study, male Wistar rats received an intraperitoneal injection of $0.1,1,5$ and 10 $\mu \mathrm{g} / \mathrm{kg}$ body weight of $\mathrm{Cn}$ as a stimulant to bring about zymogen granule release. An intraperitoneal injection of $1 \mu \mathrm{g} / \mathrm{kg}$ body weight of $\mathrm{Cn}$ caused a marked decrease in the number of zymogen granules in almost all of the teleinsular acinar cells within 15 min, and the decrease in number of zymogen granules was completely recovered by $4 \mathrm{~h}$ after intraperitoneal injection. Significant changes in the number of zymogen granules were not found in the $0.1 \mu \mathrm{g} / \mathrm{kg} \mathrm{Cn}$ group. Edematous swelling of the exocrine pancreas occurred in 5 and $10 \mu \mathrm{g} / \mathrm{kg}$ Cn groups. Therefore, an intraperitoneal injection of $1 \mu \mathrm{g} / \mathrm{kg}$ body weight of $\mathrm{Cn}$ was chosen for the present experiment.

\section{Secretion of zymogen granules}

To investigate TBTO effects on the secretion of zymogen granules from exocrine pancreatic acinar cells, male Wistar rats were divided into 4 groups (three in each group). Groups 1 and 2 received an intramuscular injection of $0.5 \mathrm{ml} / \mathrm{kg}$ body weight of TBTO and served as TBTO $(+)$ groups. Groups 3 and 4 received the same dose of distilled water and served as TBTO (-) groups. Six h after injection, animals of Groups 1 and 3 received $1 \mu \mathrm{g} / \mathrm{kg}$ body weight of caerulein $(\mathrm{Cn})$ (Bachem, Inc., CA, USA, purity: 98\%) intraperitoneally and served as $\mathrm{Cn}(+)$ groups, and Groups 2 and 4 received the same dose of intraperitoneal injection of distilled water and served as $\mathrm{Cn}(-)$ controls. At $15 \mathrm{~min}$ after injection, all animals were deeply anesthetized and each pancreas was isolated and prepared for electron microscopy as described above.

\section{Synthesis of zymogen granules}

To investigate TBTO effects on the synthesis of 
zymogen granules in the acinar cells, 9 male Wistar rats were divided into Groups 5, 6 and 7 (three in each group). All animals received an intraperitoneal injection of $1 \mu \mathrm{g} / \mathrm{kg}$ body weight of $\mathrm{Cn}$. At 15 min after $\mathrm{Cn}$ injection, Group 5 animals were deeply anesthetized and each pancreas was isolated and prepared for electron microscopy to then serve as controls, Group 6 received an intramuscular injection of $0.5 \mathrm{ml} / \mathrm{kg}$ body weight of TBTO, and Group 7 received the same dose of distilled water. At $6 \mathrm{~h}$ after $\mathrm{Cn}$ injection, animals of Groups 6 and 7 were deeply anesthetized and each pancreas was isolated and prepared for electron microscopy as described above.

\section{Calculation and statistical analysis of the number of zymogen granules}

Forty electron micrographs of teleinsular acini of the exocrine pancreas at an original magnification of 3,000 times were randomly selected from each group, and printed at a final magnification of 9,000 times. Four acinar cells facing an acinar lumen were chosen in each micrograph, and the number of zymogen granules from each acinar cell was counted. Data were statistically analyzed by a Student t-test.

\section{RESULTS}

No death or weight loss occurred among the experimental animals undergoing TBTO and/or Cn treatments, and all treated rats appeared in good condition. No local necrosis was found at the injection site.

Data obtained from atomic absorption analyses of tin concentrations in the blood are shown in Figure 1. The blood tin concentration peaked approximately $1 \mathrm{~h}$ after TBTO injection and then progressively declined. The mean concentration of tin in the blood reached the zero level at $12 \mathrm{~h}$ after TBTO treatment.

In control rats, the acinar cells contained a large number of rough surfaced endoplasmic reticulum in the basal cytoplasm, and the apical cytoplasm was filled with abundant electron dense zymogen gran-

Fig. 4 A. A tin (Sn) L-alpha peak $(3.44 \mathrm{keV})$ obtained from one of the swollen mitochondria in Figure 3 by energy dispersive X-ray microanalysis. B. An X-ray spectrum from the cytoplasm adjacent to the swollen mitochondria in Figure 3. No tin peak has been obtained. In these spectra, the osmium peak arises from the fixative, the chloride peak from epoxy resin, copper and chromium peaks from a specimen holder of the electron microscope, and the molybdenum peak from the molybdenum grid. The origin of the aluminum peak is unknown. ules. An abundance of condensing vacuoles of relatively low electron density existed in the region of the Golgi complexes (Fig. 2A, B).

No significant morphological alterations were observed in the exocrine pancreas until $1 \mathrm{~h}$ after TBTO treatment. However, a marked swelling of mitochondria and an enlargement of the cisterns of the rough surfaced endoplasmic reticulum appeared in the acinar cells of the exocrine pancreas at $2 \mathrm{~h}$ after TBTO treatment. Matrices of such swollen mitochondria showed a lighter appearance, and some of their cristae were destroyed (Fig. 3). Using energy dispersive X-ray microanalysis, apparent tin L-alpha peaks $(3.44 \mathrm{keV})$ were obtained from these swollen mitochondria (Fig. 4A). However, such tin peaks were not detected in any other components of the
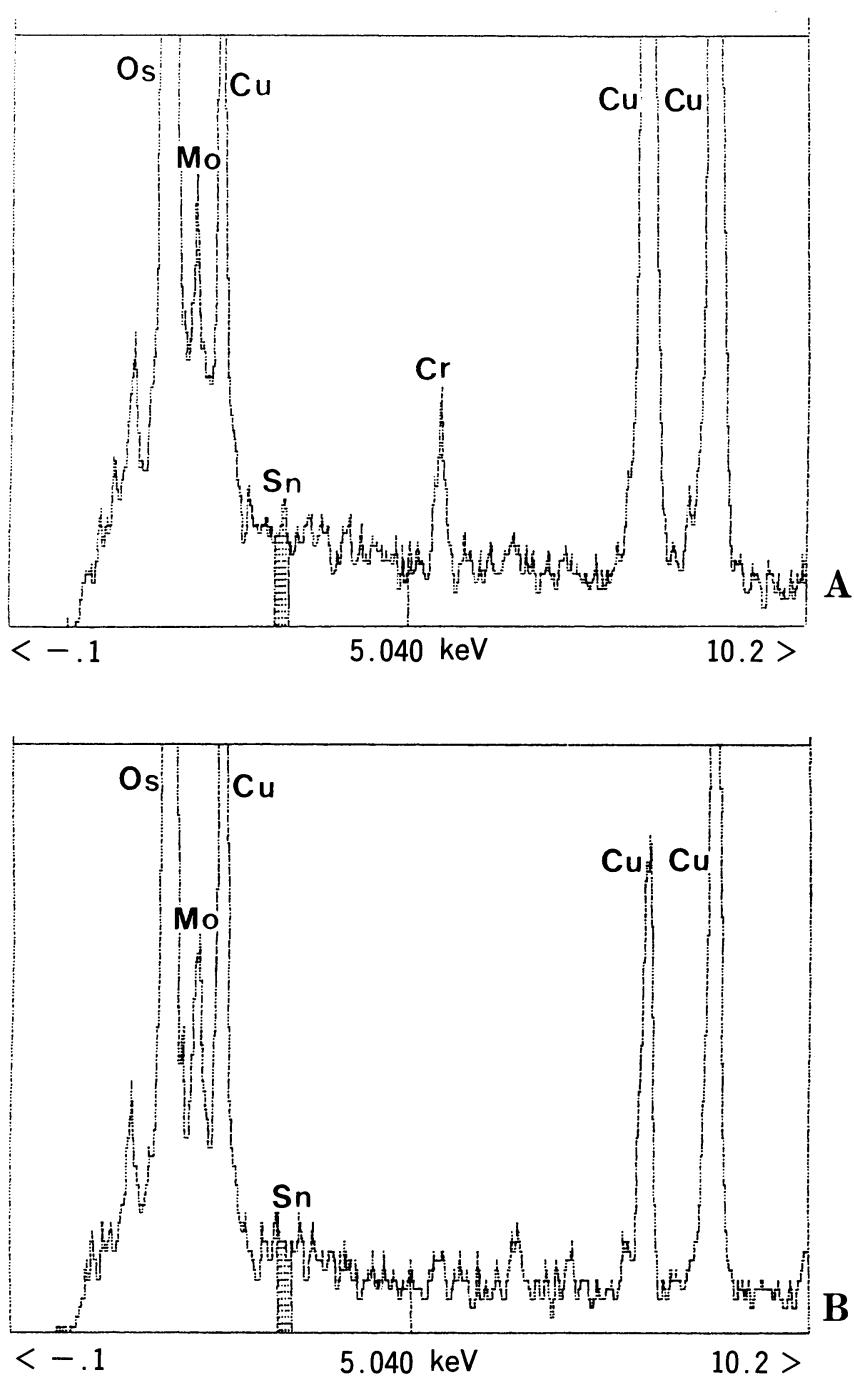

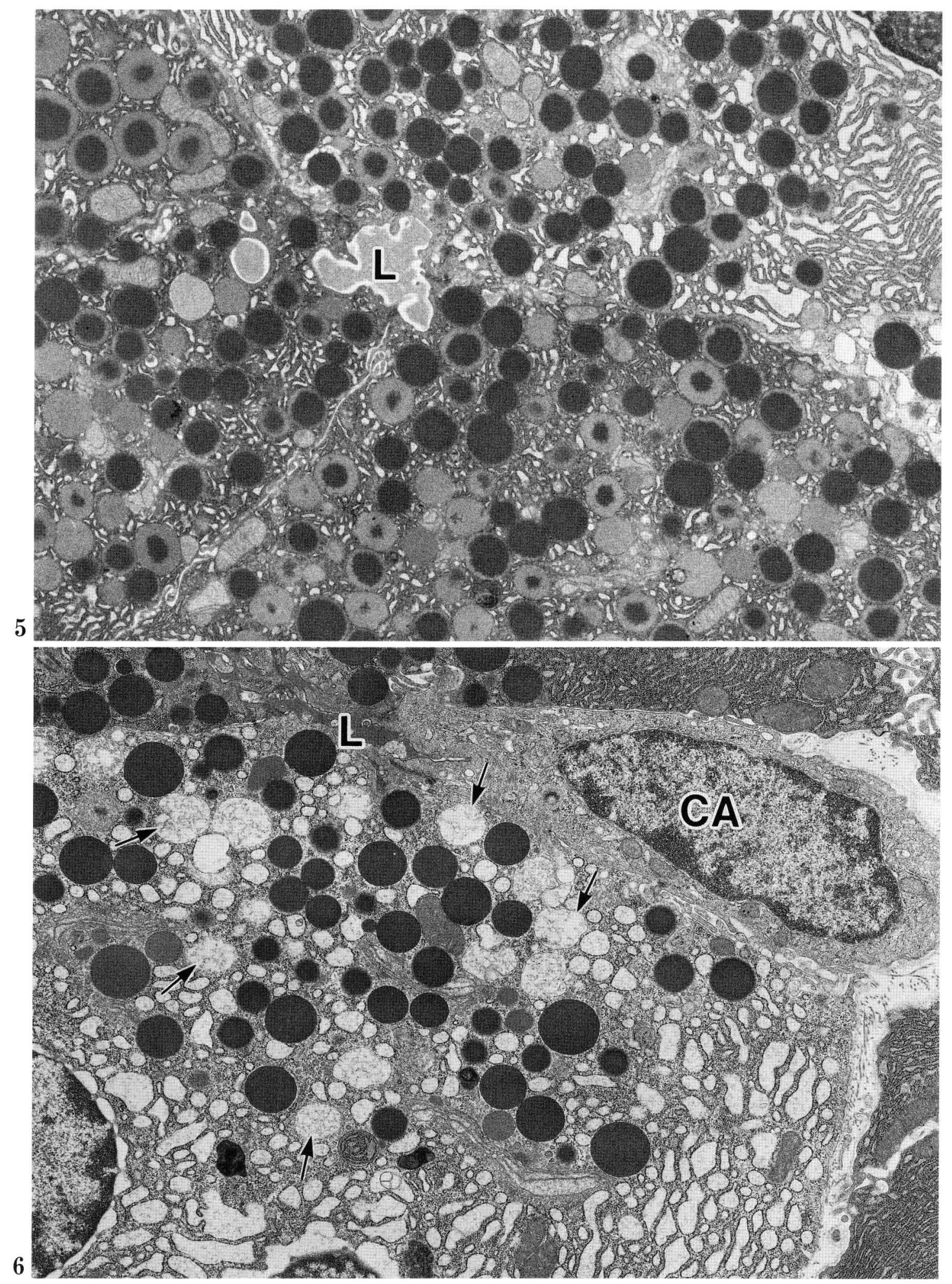

Fig. 5. Heterogeneous zymogen granules with an electron dense core and a pale cortical zone are often found in the acinar cells at $2 \mathrm{~h}$ after TBTO treatment. $L$ acinar lumen. $\times 9,000$

Fig. 6. Dilated cisterns of the rough surfaced endoplasmic reticulum (arrows) are found throughout the cytoplasm of the acinar cells between 4 and $8 \mathrm{~h}$ after TBTO treatment. $C A$ centroacinar cell, $L$ acinar lumen. $\times 10,000$ 

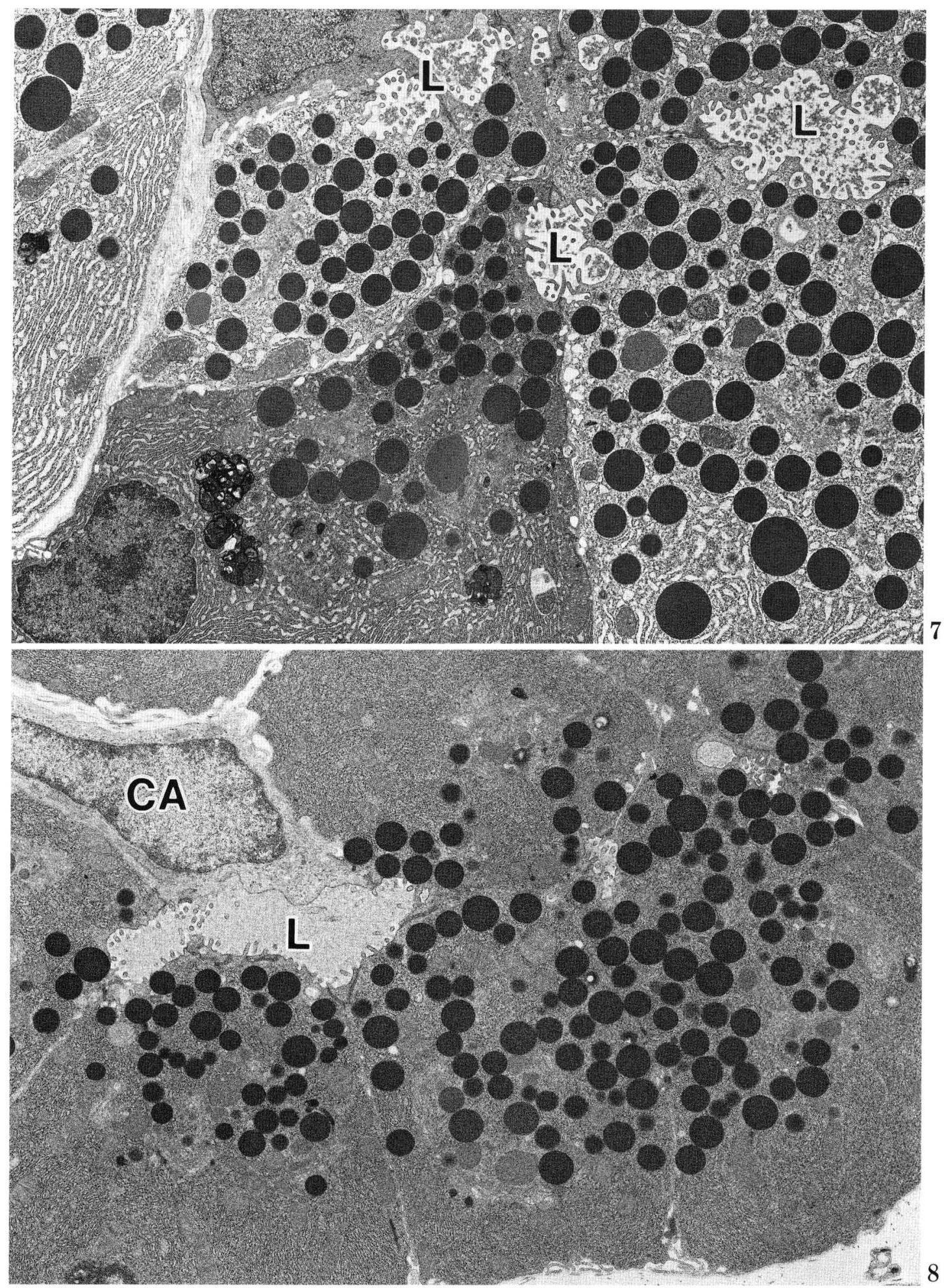

Fig. 7. An electron micrograph of the acinar cells at $12 \mathrm{~h}$ after TBTO treatment, showing ultrastructural signs of restoration. The apical cytoplasm is filled with electron dense zymogen granules, and the arrangement of rough surfaced endoplasmic reticulum in the basal cytoplasm has become compact. $L$ acinar lumen. $\times 6,600$

Fig. 8. The ultrastructure of the acinar cells appears to be recovered at $24 \mathrm{~h}$ after TBTO treatment. $C A$ centroacinar cell, $L$ acinar lumen. $\times 4,600$ 


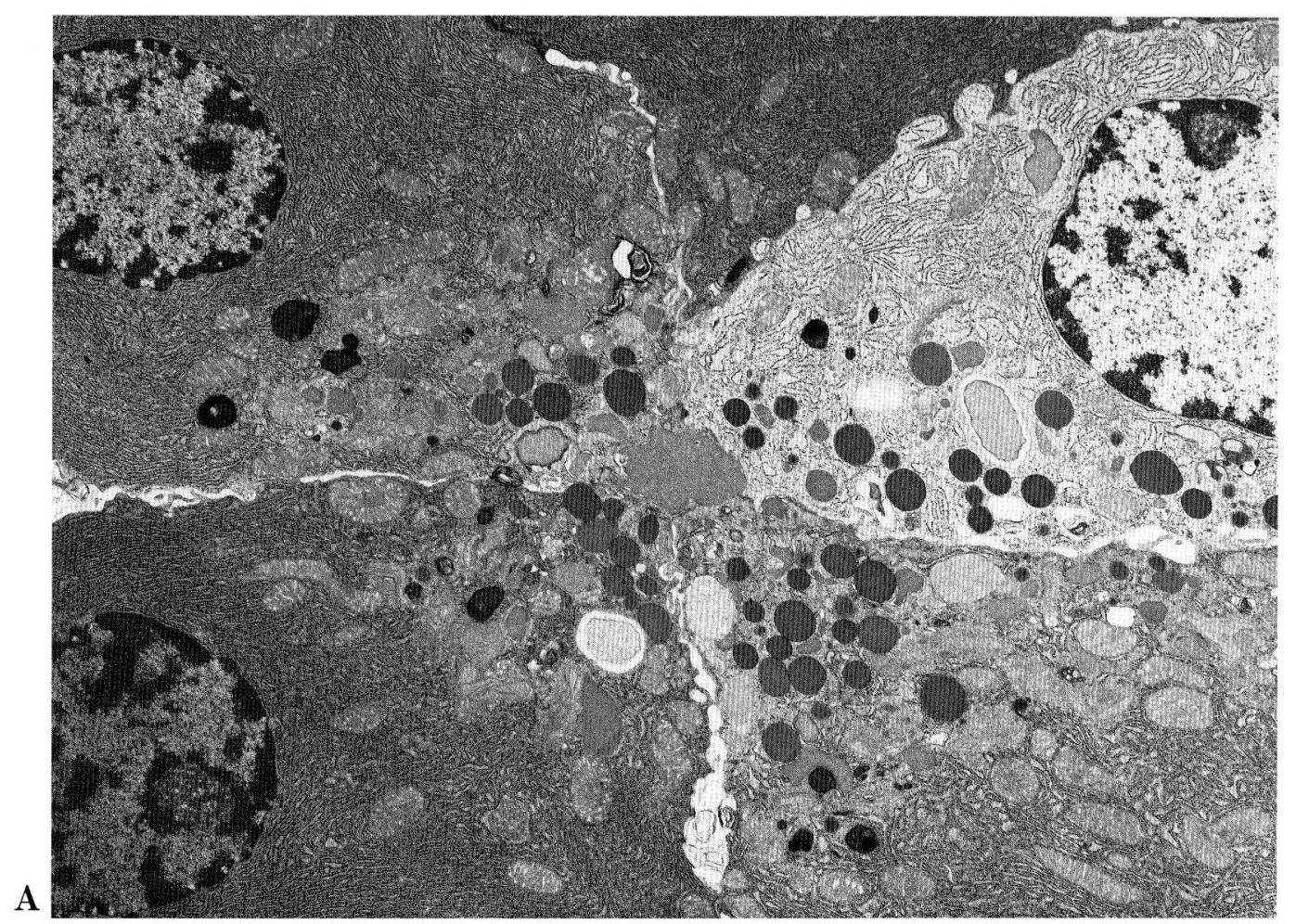

A

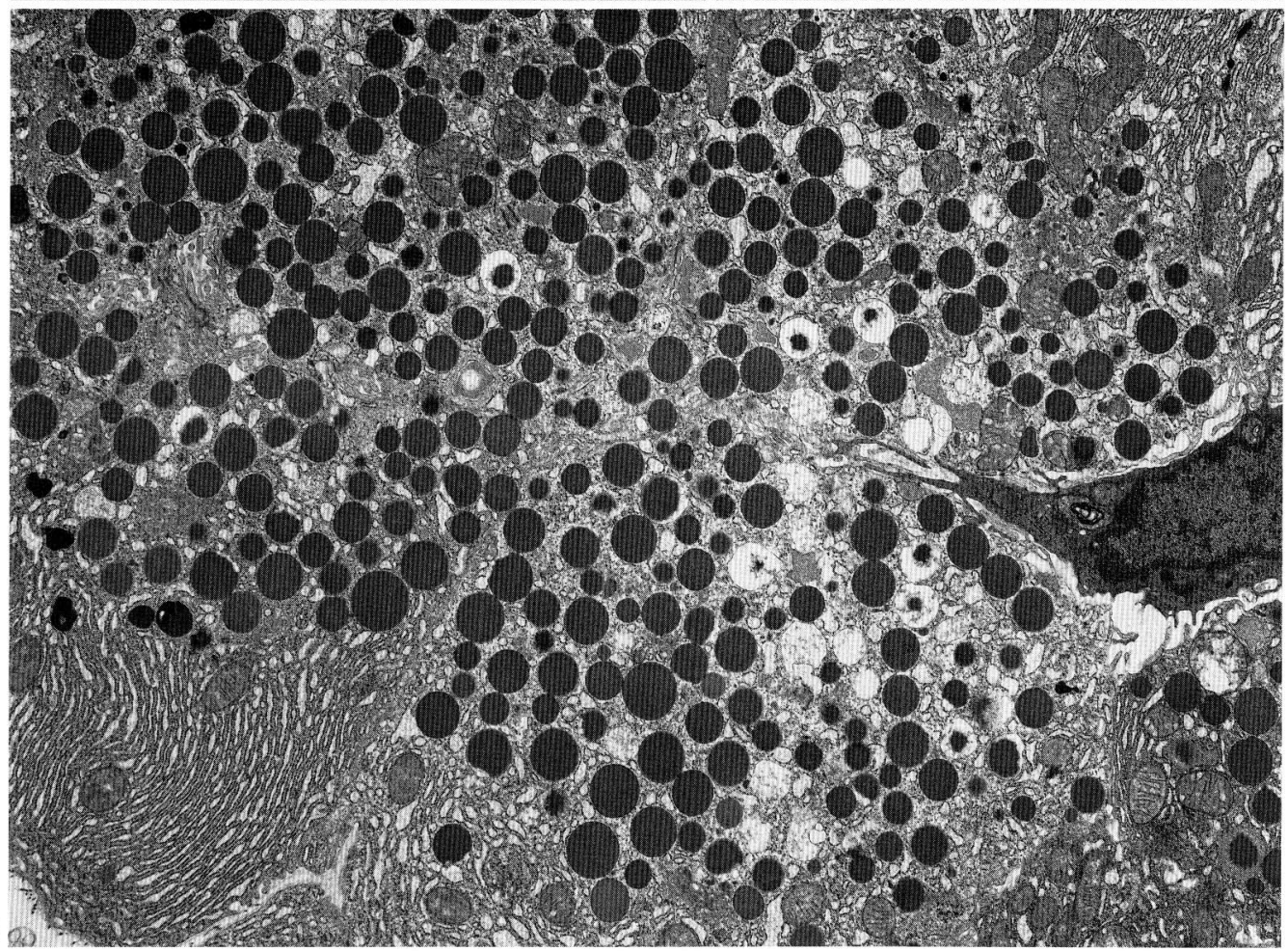

Fig. 9 A. In TBTO (-) control rats, Cn injection causes a significant decrease in the number of zymogen granules in the teleinsular acinar cells within 15 min (Group 3). $\times 6,700$. B. In TBTO treated animals, $\mathrm{Cn}$ injection does not affect the number of zymogen granules (Group 1). ×6,700 

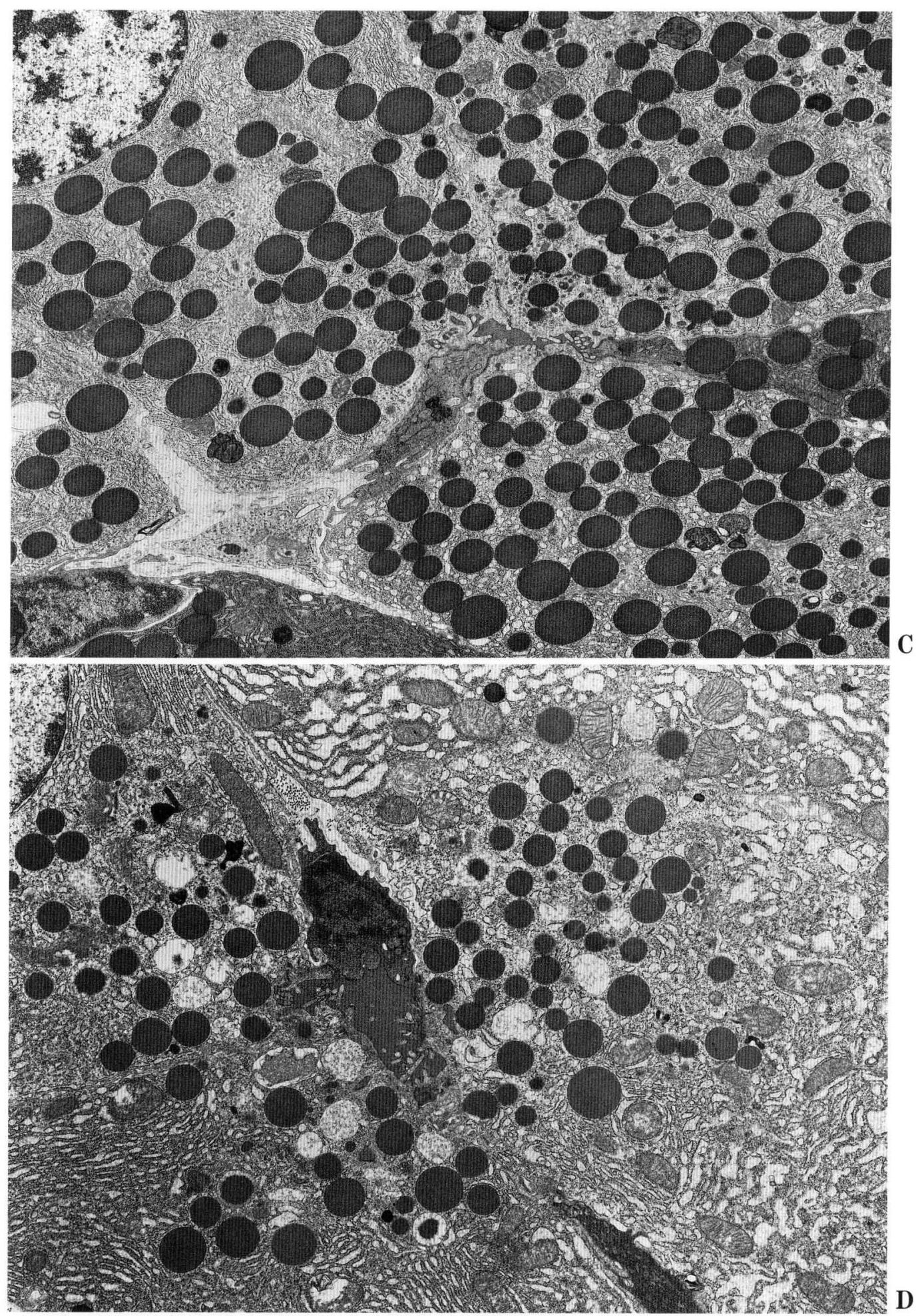

Fig. 9 C. Recovery of the number of zymogen granules is seen in the TBTO $(-)$ control acinar cells at $6 \mathrm{~h}$ after $\mathrm{Cn}$ injection (Group 7). $\times 6,700$. D. The increase in number of zymogen granules has not occurred in the TBTO treated acinar cells by $6 \mathrm{~h}$ after $\mathrm{Cn}$ injection (Group 6). $\times 6,700$ 
acinar cells or other regions in the pancreas tissue throughout the TBTO experiment (Fig. 4B). Heterogeneous zymogen "granules, which had an electron dense core and a paler cortical zone, were often found in the acinar cells of TBTO treated animals only. The density of the dense cores of these bipartite granules was seen to be similar to that of the mature zymogen granules, and the density of the pale cortical zone was similar to that of the condensing vacuoles in the Golgi region (Fig. 5). Between 4 and $8 \mathrm{~h}$ after TBTO treatment, the swelling of mitochondria and the enlargement of cisterns of the rough surfaced endoplasmic reticulum were still apparent in the acinar cells (Fig. 6). However, tin peaks by X-ray microanalysis were not detected from the swollen mitochondria at this period. During the course of this experiment, the ultrastructures of the centroacinar cells appeared to be unaltered as shown in Figure 6.

At $12 \mathrm{~h}$ after TBTO treatment, although some residual bodies and irregular shaped zymogen granules were found in the cytoplasm of acinar cells, cisterns of the rough surfaced endoplasmic reticulum showed a regular arrangement and the apical cytoplasm was filled with electron dense zymogen granules, indicating restoration of the acinar cells (Fig. 7). As shown in Figure 8, the recovery of the acinar cells is ultrastructurally accomplished by $24 \mathrm{~h}$ after TBTO injection.

To clarify the effects of TBTO on the secretion of zymogen granules, $\mathrm{Cn}$ was used as a stimulant for zymogen granule secretion with or without TBTO treatment. Data from the calculation and statistical analysis of the number of zymogen granules are shown in Table 3. In Groups 3 and 4, which did not receive TBTO, the number of zymogen granules in the acinar cells significantly decreased at 15 min after $\mathrm{Cn}$ injection $(\mathrm{p}<0.001)$. An ultrastructural example is shown in Figure 9A. However, the difference in the number of zymogen granules was not significant

Table 3. Effects of TBTO on the secretion of zymogen granules (Number of zymogen granules/acinar cells).

\begin{tabular}{ccc}
\hline & Controls & 15 min after Cn injection \\
\hline TBTO $(-)$ & $\begin{array}{c}82.000 \pm 4.025 \\
(\text { Group 4. } \mathrm{n}=160)\end{array}$ & $\begin{array}{c}19.400 \pm 2.046^{*} \\
(\text { Group 3. } \mathrm{n}=160)\end{array}$ \\
& & \\
TBTO $(+)$ & $\begin{array}{c}72.525 \pm 2.828 \\
(\text { Group 2. } \mathrm{n}=160)\end{array}$ & $\begin{array}{c}68.575 \pm 2.157 \\
(\text { Group 1. } \mathrm{n}=160)\end{array}$ \\
\hline
\end{tabular}

All values expressed as mean $\pm \mathrm{SE}$

Statistical analyses were carried out by a Student t-test

${ }^{*}$ Significantly different from the control value $(p<0.001)$ before (Group 2) and after (Group 1) Cn injection in TBTO treated animals. An ultrastructural example of Group 1 is shown in Figure 9B.

To determine the effects of TBTO on the synthesis of zymogen granules, the number of zymogen granules was counted after a $\mathrm{Cn}$ injection with or without subsequent TBTO treatment. Data from the calculation and statistical analysis of the number of zymogen granules are shown in Table 4 . The animals that did not receive TBTO treatment (Group 7) showed a significant increase in the number of zymogen granules at $6 \mathrm{~h}$ after $\mathrm{Cn}$ injection in comparison with that of controls (Group 5) $(\mathrm{p}<0.001)$, as shown in Figure $9 \mathrm{C}$. However, the increase in the number of the granules was not significant in TBTO treated rats (Group 6), as shown in Figure 9D.

Table 4. Effects of TBTO on the synthesis of zymogen granules (Number of zymogen granules/acinar cells).

\begin{tabular}{ccc}
\hline 15 min after & \multicolumn{2}{c}{$6 \mathrm{~h}$ after Cn injection } \\
\cline { 2 - 3 } $\begin{array}{c}\text { Control } \\
(\text { Group } 5 . \mathrm{n}=160)\end{array}$ & $\begin{array}{c}\text { TBTO }(-) \\
(\text { Group } 7 . \mathrm{n}=160)\end{array}$ & $\begin{array}{c}\text { TBTO }(+) \\
\text { Group 6. } \mathrm{n}=160)\end{array}$ \\
\hline $19.375 \pm 3.490$ & $65.900 \pm 2.187^{*}$ & $23.900 \pm 2.054$ \\
\hline
\end{tabular}

All values expressed as mean $\pm \mathrm{SE}$

Statistical analyses were carried out by a Student t-test ${ }^{*}$ Significantly different from the control value $(p<0.001)$

\section{DISCUSSION}

In the present experiment, a transient but marked swelling of mitochondria appeared as the earliest morphological change in the exocrine pancreatic acinar cells attributable to TBTO treatment. The swelling of mitochondria in organo-tin intoxication has been reported for in vitro (STOCKDALE et al., 1970) and for in vivo endothelial cells of the rat cornea (YoshizUKA et al., 1991a) and aorta (YosHizUKA et al., 1992a), for hepatocytes (YoshizUKA et al., 1992b) and for striated duct epithelial cells of the submandibular gland (YosHIzUKA et al., 1992c). Since organo-tin compounds are known to disturb the oxidative phosphorylation of mitochondria and to inhibit the production of the intracellular adenosine triphosphate (ATP) (ALDRIDGE, 1958; YosHIzUKA et al., 1992b), the swelling of mitochondria, which transiently occurred in the acinar cells, may be a morphological manifestation of the mitochondrial dysfunctions induced by toxic effects of TBTO. 
The enlargement of cisterns of the rough surfaced endoplasmic reticulum was also noted in the TBTOtreated rat pancreatic acinar cells. Many zymogen granules decreased in electron density. Heterogeneous granules and pale granules increased in number, whereas the number of mature electron dense zymogen granules decreased. It is therefore reasonable to consider that both the disturbance of ATP production and the reduction of cellular ATP content cause such morphological alterations of zymogen granules.

It was reported that cycloheximide, which is a drug known to inhibit cytosolic protein synthesis, induces the dilatation of cisterns of the rough surfaced endoplasmic reticulum (FUנIMOTO, 1975; YoshizuKA et al., 1991b). To clarify whether TBTO inhibits the synthesis of zymogen granules, another experiment was carried out. The results as shown in Table 4 clearly indicate that the formation of zymogen granules was inhibited in the TBTO-treated rats. These data suggest that the enlargement of cisterns of the rough surfaced endoplasmic reticulum and the decrease in number of mature zymogen granules, which were exclusively found in the TBTO-treated rat pancreatic acinar cells, resulted from a decrease in the protein synthesis activity of these cells mainly due to mitochondrial dysfunctions.

Moreover, we performed another experiment to investigate whether TBTO affects the secretion of zymogen granules. Data obtained from this experiment, as shown in Table 3, indicated that $\mathrm{Cn}$ injection induced a marked decrease in the number of zymogen granules in the exocrine pancreatic acinar cells in control rats. However, the secretion of zymogen granules in TBTO-treated animals was not significant when stimulated with $\mathrm{Cn}$. The discharge of zymogen granules is known to require an energy supply and calcium ions (PALADE, 1975). Intracellular calcium ions, which are reserved in mitochondria and cisterns of rough surfaced endoplasmic reticulum, play a role in initiating the $\mathrm{Cn}$ stimulated secretion response (Williams et al., 1989). The mechanism of the inhibitory action of TBTO on the secretion of zymogen granules remains unclean. However, the disturbance of the energy supply due to mitochondrial dysfunction may play a role in this phenomenon. Recently, PRASADA RAO et al. (1991) reported that organo-tin compounds inhibit the transport of calcium ions into the cardiac sarcoplasmic reticulum in vitro. Further studies are necessary to elucidate the interactions of TBTO with calcium ions in pancreatic acinar cells.

\section{REFERENCES}

Aldridge, W. N.: The biochemistry of organotin compounds. Trialkyltins and oxidative phosphorylation. Biochem. J. 69: 367-379 (1958).

BARnes, J. M. and P. N. MAgeE: The biliary and hepatic lesion produced experimentally by dibutyltin salts. J. Pathol. Bacteriol. 75: 267-279 (1958).

BOYER, I. J: Toxicity of dibutyltin, tributyltin and other organotin compounds to humans and to experimental animals. Toxicology 55: 253-298 (1989).

Fuлiмото, S.: Ultrastructural alterations in rabbit taste buds induced by prolonged treatment with cycloheximide. Arch. Histol. Jap. 38: 31-42 (1975).

HensChleR, D.: Tri-n-butyltin compounds. In: (ed. by) D. HENSCHLER: Occupational toxicants: critical data evaluation for MAK values and classification of carcinogens, Vol. 1. VCH Verlagsgesellschaft mbH, Weinheim, 1991 (p. 315-333).

Manabe, S. and O. WAdA: Triphenyltin fluoride (TPTF) as a diabetogenic agent. TPTF induces diabetic lipemia by inhibiting insulin secretion from morphologically intact rabbit B-cell. Diabetes 30: 1013-1021 (1981).

Merkord, J., L. Jonas and G. Hennighausen: Morphological lesions of pancreas and bile ducts in rats induced by dibutyltin dichloride. Arch. Toxicol. Suppl. 14: 75-79 (1991).

Palade, G.: Intracellular aspects of the process of protein synthesis. Science 189: 347-358 (1975).

Prasada RaO, K. S., J. A. Cameron, P. R. Yallapragada, P. J. S VIG and D. Desaiah: Inhibition of $\mathrm{Ca}^{2+}$ transport associated with cAMP-dependent protein phosphorylation in rat cardiac sarcoplasmic reticulum by triorganotins. Arch. Toxicol. 65: 311-317 (1991).

Stockdale, M., A. P. Dawson and M. J. Selwyn : Effects of trialkyltin and triphenyltin compounds on mitochondrial respiration. Europ. J. Biochem. 15: 342-351 (1970).

WADA, 0. and S. MANABE: Biochemistry, pharmacodynamics and kinetics of tributyltin compounds. In: (ed. by) ORTEP Association: Toxicology and analytics of the tributyltins. The present status (Proceedings of an ORTEP workshop. Berlin, 15-16 May, 1986). ORTEP Association, Vlissingen-Oost, The Netherlands, 1987 (p. 113-121).

WHO: Tributyltin compounds (Environmental Health Criteria Vol. 116). World Health Organization, Geneva, 1990.

Williams, J. A., D. B. Burnham and S. R. Hootman: Cellular regulation of pancreatic secretion. In: (ed. by) V. B. Mountcastle, F. E. Bloom and S. R. Geiger: Handbook of physiology, Gastrointestinal system III, Chap. 21. American Physiology Society, Bethesda, 1989 (p. 419-441).

Yoshizuka, M., N. Haramaki, M. YoKoYama, K. HaRa, A. Kawahara, Y. UmezU, H. Araki, N. Mori and S. Fujimoto: Corneal edema induced by bis (tributyltin) oxide. Arch. Toxicol. 65: 651-655 (1991a). 
Yoshizuka, M., N. Mori, K. Hamasaki, I. Tanaka, M. Yokoyama, K. Hara, Y. DoI, Y. Umezu, H. ARaki, Y. Sakamoto, M. MiYazaki and S. Fujimoto: Cadmium toxicity in the thyroid gland of pregnant rats. Exp. Mol. Pathol. 55: 97-104 (1991b).

YoshizuKa, M., K. HaRa, Y. DoI, N. Mori, M. Yokoyama, E. ONo and S. Fujimoto: The toxic effects of bis (tributyltin) oxide on the rat thoracic aorta. Histol. Histopathol. 7: 445-449 (1992a).

Yoshizuka, M., K. Hara, N. Haramaki, M. Yokoyama, N. Mori, Y. Doi, A. Kawahara and S. Fujimoto: Studies on the hepatotoxicity induced by bis (tributyltin) oxide. Arch. Toxicol. 66: 182-187 (1992b).

Yoshizuka, M., K. Hara, N. Nagata, Y. DoI, M. Yokoyama, T. Sagara and S. Fujimoto: The role of the rat submandibular gland in the excretion of bis (tributyltin) oxide: electron microscopy, X-ray microanalysis and atomic absorption analysis. Tiss. Cell 24: 725-733 (1992c).

Dr. Kazuo HaRA

Department of Anatomy University of Occupational and Environmental Health School of Medicine 1-1 Iseigaoka, Yahatanishi-ku Kitakyushu, 807 Japan

原一生 807 北九州市八幡西区医生ケ丘1-1 産業医科大学 解剖学第二講座 